\title{
Process of Facilitated Extraction of Vanadium Ions through Supported Liquid Membranes: Parameters and Mechanism
}

\author{
O. Kamal, ${ }^{1,2}$ T. Eljaddi, ${ }^{1}$ El H. El Atmani, ${ }^{1}$ I. Touarssi, ${ }^{1}$ I. Mourtah, ${ }^{1}$ \\ L. Lebrun, ${ }^{2}$ and M. Hlaïbi ${ }^{1,2}$ \\ ${ }^{1}$ Laboratoire Génie des Matériaux pour l'Environnement et la Valorisation (GeMEV), Université Hassan II, \\ Faculté des Sciences Aïn Chock, BP 5366, Maârif, Casablanca, Morocco \\ ${ }^{2}$ Laboratoire des Polymères, Biopolymères, Surfaces, UMR 6270 du CNRS, Université de Rouen, Faculté des Sciences, \\ 76821 Mont-Saint-Aignan, France
}

Correspondence should be addressed to O. Kamal; koussamasmc5@yahoo.fr

Received 14 July 2016; Revised 31 October 2016; Accepted 8 November 2016; Published 26 March 2017

Academic Editor: Michael Aizenshtein

Copyright (c) 2017 O. Kamal et al. This is an open access article distributed under the Creative Commons Attribution License, which permits unrestricted use, distribution, and reproduction in any medium, provided the original work is properly cited.

\begin{abstract}
To conduct experiments related to the facilitated extraction phenomenon of vanadium ions $\left(\mathrm{VO}_{2}^{+}\right)$, three supported liquid membranes (SLMs) were prepared, each containing $0.01 \mathrm{M}$ of methyl cholate (MC), resorcinarene (RESO), or trioctylamine (TOA) as extractive agents. Kinetic and thermodynamic models were developed, based on the interaction of the substrate $\left(\mathrm{VO}_{2}{ }^{+}\right)$with the extractive agent $T$ and the diffusion of the formed entity (TS) through the membrane. The experimental results verify the models, and to determine, macroscopic parameters, permeabilities $(P)$ and initial fluxes $\left(J_{0}\right)$, and microscopic parameters, association constants $\left(K_{\text {ass }}\right)$ and apparent diffusion coefficients $\left(D^{*}\right)$ related to formed entities $(T S)$ and their diffusion through the membrane organic phase. The experimental results indicate that the mechanism on the migration of the $\mathrm{VO}_{2}{ }^{+}$ions through the membrane organic phase is based on the successive jumps of substrate, from one site to another of the extractive agent. To explain these results and understand the mechanism, we studied influence of temperature factor, and we determined activation parameters $\left(E_{a}\right.$, $\Delta H^{\ddagger}$, and $\Delta S^{\ddagger}$ ). The results show that this extraction phenomenon is governed by a structural term. Therefore, the membrane performance changes according to nature and structure of the association site presented by each of extractive agents.
\end{abstract}

\section{Introduction}

Conventional industrial techniques of extraction and separation by distillation or crystallization have a high cost, since they require large amounts of energy and use polluting organic solvents. The technique of liquid-liquid extraction is cheaper, but it requires large amounts of volatile organic solvents, often considered pollutants to the environment, which limits its use. Membrane processes for separation and recovery are more economical because they can operate at standard temperature and pressure and with very small amounts of organic solvents [1,2].

The supported liquid membranes (SLMs) are part of these membrane processes types; they have a major economic and environmental interest, since they are necessary for the treatment of liquid mediums, contaminated with metal ions or organic compounds. These membrane types (SLMs) are prepared from inert polymer support; in fact, an organic solution containing a hydrophobic extractive agent is incorporated usually by immersion of this polymeric support. Polypropylene remains a widely used polymer support, for its high porosity, which generates large fluxes of metal ions through these membrane types. The supported liquid membrane processes have several advantages compared to the liquid-liquid extraction phenomenon. In particular, a very low uses of organic solvents, which today an important criterion for the protection of the environment and the treatment of toxic effluents. These processes permit continuous operation in a single step, since the two steps extraction and reextraction are so coupled to the two interfaces. Indeed, the membranes are thin films that separate two fluids; an essential property of membranes is their permeability and therefore 
their ability to allow the passage of only certain species from one environment to another, while acting as a barrier to other species.

Studies based on the use of supported liquid membranes for removing some toxic metal ions from concentrated acid solutions are very numerous; the interest in this study was focused on the phenomenon of facilitated transport and extraction of $\mathrm{VO}_{2}{ }^{+}$ions. Indeed, vanadium is often present as an impurity during the process of manufacturing industrial phosphoric acid by the wet process, in which sulfuric acid is used to dissolve the phosphate ores. The obtained liquor is a complex solution composed of organic and inorganic impurities. Among these impurities, vanadium ions in high concentrations around $600 \mathrm{mg} \mathrm{L}^{-1}$, this is a potential source of vanadium element [3].

In the present work, we try to use the SLMs technique for the facilitated extraction of vanadium ions $\left(\mathrm{VO}_{2}{ }^{+}\right)$from acid environments. This technique is based on work carried out by the principle of substrate transport by membrane processes, such as facilitated transport through liquid membranes. The used supported liquid membranes consist of a microporous inert polymeric support polyvinylidene difluoride (PVDF), a thickness of $100 \mu \mathrm{m}$, and a porosity of $60 \%$ with pores of $0.45 \mu \mathrm{m}$ in diameter. For each of the prepared membranes, this support will be impregnated with organic solution toluene in $0.01 \mathrm{M}$ concentration for each following carrier agents: methyl cholate (MC), resorcinarene (RESO), or trioctylamine (TOA). Kinetic and mechanistic models have been developed and tested to the facilitated extraction phenomenon of $\mathrm{VO}_{2}{ }^{+}$ions from acid solutions. The macroscopic parameters, permeabilities $P$, and initial fluxes $J_{0}$ were determined and related to the microscopic parameters, the apparent diffusion coefficient $D^{*}$ and the association constant $K_{\text {ass }}$ characteristics of the formation of entity "Extractive agent-Substrate" (TS) and its diffusion across organic phase [4-7]. For a better understanding of this phenomenon, the explanation of the results and the identification of the mechanism for this process, we studied the temperature factor influence on the evolution of the parameters $P, J_{0}, D^{*}$, and $K_{\text {ass }}$, as well as the performance of adopted SLMs. Similarly, we determined the activation parameters, energy $E_{a}$, enthalpy $\Delta H^{\neq}$, and entropy $\Delta S^{\neq}$, in order to know the factor that governs the movement of $\mathrm{VO}_{2}{ }^{+}$ ions during their passage through the membrane organic phase.

\section{Material and Methods}

2.1. Description and Operating Principle of a SLM. The SLMs consist of an organic solvent immobilized by capillary forces in the pores of a polymeric support, separating the source and the receiving phases. The support of these membranes is generally an hydrophobic inert polymer which is characterized by a small thickness of 25 to $100 \mu \mathrm{m}$ and pore diameters of 0.12 to $1 \mu \mathrm{m}[3,4]$. The diffusion of chemical species through these membranes is an interfacial phenomenon; the use of a support having a high porosity is necessary to increase the contact area and the selectivity to the diffusion of species

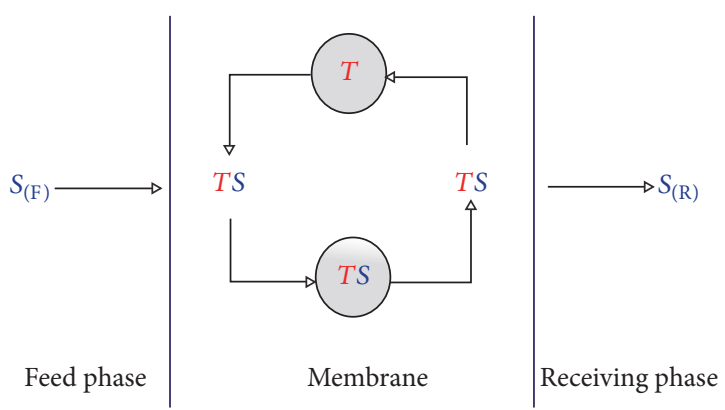

FIGURE 1: Facilitated transport and extraction mechanism through a SLM.

and very important to operate in the best conditions of extraction and separation through the SLMs [4]. To improve the separation process, the researchers added to the organic phases of SLMs mobile extractive agents, which accelerate and facilitate the extraction of species, while increasing the selectivity of these membrane types [8-11]. In addition, the technical SLM approach is widely used for the extraction and enrichment of metal ions and some organic compounds [12-14]. Indeed, this technique has been used to study the facilitated transport and apply it to the selective extraction and enrichment of varied organic compounds, such as amino acids $[15,16]$, amino-aromatic phosphates [17], sugars [18$20]$, herbicides [21, 22], and organic acids [23, 24].

This method, which is called facilitated transport or extraction through supported liquid membranes, is based on the recognition of a substrate $(S)$ by a extractive agent molecule $(T)$. This process involves the mobility within the membrane organic phase of a complex $(S T)$ produced by a reversible forming reaction, between the agent $(T)$ and the transported substrate $(S)$, which takes place at membrane interfaces with the source and receiving phases. This facilitated extraction phenomenon through the SLMs is a cyclical process which is based on the five following successive steps:

(1) Diffusion of the substrate $(S)$ in the feed phase to the membrane interface

(2) Formation of substrate-carrier complex (ST) at the interface source phase membrane

(3) Diffusion of entity (ST) through the membrane organic phase to the interface membrane-receiving phase

(4) Dissociation of entity (ST) at the interface membrane receiving phase

(5) Diffusion of free substrate $(S)$ in the receiving phase and the extractive agent $(T)$ in the membrane organic phase to perform a new cycle (interaction-diffusiondissociation)

These five steps are represented by the diagram in Figure 1 and constitute the mechanism of facilitated extraction through a SLM, in which step (3) is the rate-determining step.

2.2. Cell for the Facilitated Extraction. Experiments on the transport of these ions were performed in the cell represented by the scheme in Figure 2. This cell consists of two glass 


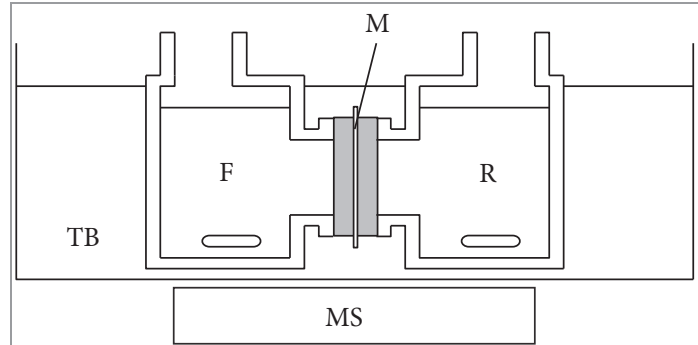

Figure 2: Scheme on the transport cell: M: SLM, F: feed source, $\mathrm{R}$ : receiving phase. TB: thermostated bath, and MS: multimagnetic stirrer.

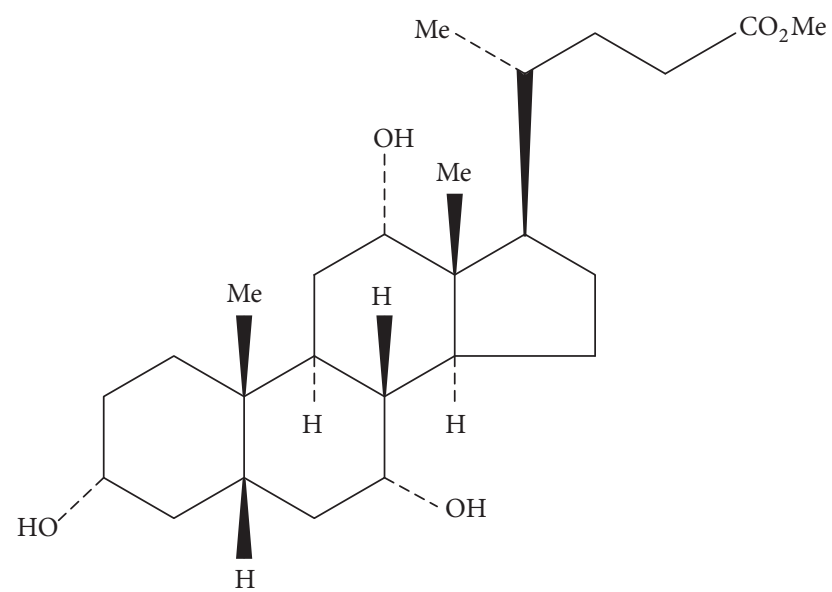

FIgURE 3: Methyl cholate structure (MC).

compartments of equal volumes $(175 \mathrm{~mL})$, separated by the microporous membrane $(\mathrm{M})$. The cell is immersed in a water bath (TB), and a multiagitator allows continuous stirring solutions in both compartments.

2.3. Experimental Section. All chemicals, reagents, and solvents were pure commercial products (Aldrich, Fluka) of analytical grade. The used solutions of vanadium ions $\mathrm{VO}_{2}{ }^{+}$ are obtained by acid hydrolysis of ammonium metavanadate $\mathrm{NH}_{4} \mathrm{VO}_{3}$. The support is a microporous polymeric film of polyvinylidene difluoride (PVDF), a thickness of $100 \mu \mathrm{m}$, a porosity of $60 \%$, and a pore diameter of $0.45 \mu \mathrm{m}$. Liquid solutions adopted for the SLM preparation consist of toluene organic phase containing $0.01 \mathrm{M}$ of one of the following extractive agents: MC, RESO, or TOA (Figures 3, 4, and 5). The three used membranes were prepared by impregnation for a 5-to-6-hour period, each of three polymer supports by one of the previous organic phases. Acidic solutions ( 0.10 to $0.0125 \mathrm{M})$ of $\mathrm{VO}_{2}{ }^{+}$ions are prepared in pure distilled water from stock solutions. Before being used, each of the prepared MLSs was treated in a conditioning step by pure water for 20 hours $[6,19]$, to remove a long induction period preceding the facilitated extraction process of a substrate by a SLM. Each used SLM was placed for a period of about 20 hours between the two compartments of the used cell for this facilitated

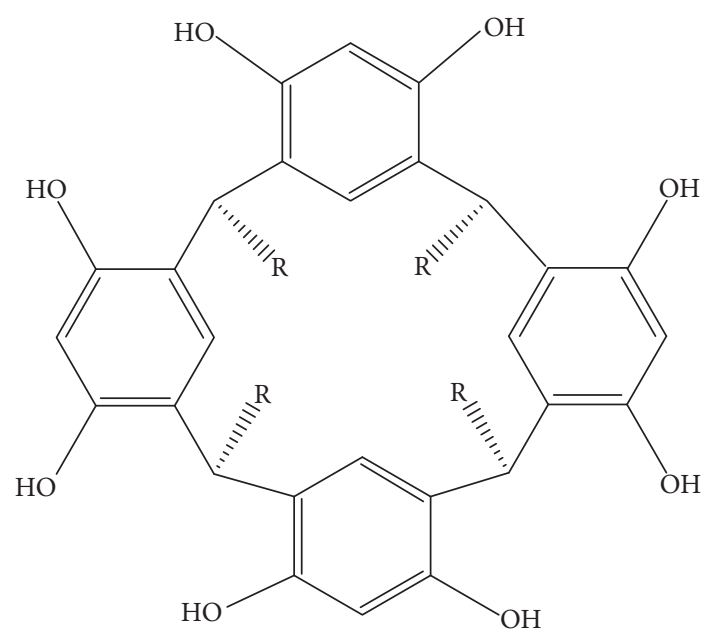

FIGURE 4: Resorcinarene structure (RESO).<smiles>CCCCCCCCN(CCCCCCC)CCCCCCCC</smiles>

FIgURE 5: Tri-n-octylamine structure (TOA).

transport process (Figure 2), filled with bidistilled pure water solution.

For experiments relating to the facilitated extraction of $\mathrm{VO}_{2}{ }^{+}$ions, the feed phase is a fixed acidity solution of nitric acid containing a known concentration of $\mathrm{VO}_{2}{ }^{+}$ions, and the receiving phase is a hydrochloric acid solution to same acidity. The two compartment solutions are maintained at the same agitation and kinetic study on the evolution of the $\mathrm{VO}_{2}{ }^{+}$ ions concentration $C_{r}$ is done by regular sampling from the receiving phase at known time intervals. These samples were analyzed by UV-visible spectroscopy, and $C_{r}$ concentration values in the receiving phase were calculated at the different time intervals as well as the term.

$\ln \left(C_{0}-2 C_{r}\right)$ versus time. Table 1 includes an example of results for facilitated extraction of $\mathrm{VO}_{2}{ }^{+}$ions from a concentrated acid medium.

\section{Theoretical Models and Calculations}

3.1. Kinetic Model and Calculation of Permeability $(P)$ and Initial Flux $\left(J_{0}\right)$. The membrane is placed between the two compartments; in source compartment, a known volume of the substrate solution $(S)$ with $C_{0}$ concentration, is introduced, and the same volume of water is placed in the receiving compartment. We carry several samples from the receiving phase at known time intervals, we note $C_{r}$ substrate concentration in this phase at time $t$, and the substrate 
TABLE 1: Results for the facilitated extraction phenomenon of $\mathrm{VO}_{2}{ }^{+}$ions by SLM containing resorcinarene extractive agent.

\begin{tabular}{lccc}
\hline$t(\mathrm{mn})$ & Absorbance & $C_{r}\left(\mathrm{~mol} \mathrm{~L}^{-1}\right)$ & $-\ln \left(C_{0}-2 C_{r}\right)$ \\
\hline 0 & 0.978 & 0 & 2.303 \\
30 & 0.039 & 0.00398 & 2.386 \\
60 & 0.052 & 0.00531 & 2.415 \\
90 & 0.085 & 0.00869 & 2.494 \\
120 & 0.114 & 0.01165 & 2.568 \\
\hline
\end{tabular}

$C_{0}=\left[\mathrm{VO}_{2}{ }^{+}\right]_{0}=0.1 \mathrm{M},\left[\mathrm{H}_{3} \mathrm{O}^{+}\right]=1 \mathrm{M},[\mathrm{RESO}]=0.01 \mathrm{M}$, and $T=293 \mathrm{~K}$.

concentration in the source phase at this time is $C_{s}=C_{0}-C_{r}$ (used support is very thin).

The equation that relates the flux $J$ to the $C_{r}$ concentration of the substrate $S$ is given by the relationship:

$$
\frac{\mathrm{d} C_{r}}{\mathrm{~d} t}=J * \frac{S}{V}
$$

where $S$ is membrane area in contact with the aqueous solutions and $V$ is the receiving phase volume.

For a quasi-static state, the flux is related to the difference in concentrations of the two compartments $\Delta C=C_{s}-C_{r}$, by Fick's first law:

$$
J=P * \frac{\Delta C}{l}
$$

where $P$ is membrane permeability and $l$ is the membrane thickness

Knowing that the membrane is very thin, then $C_{s}=C_{0}-$ $C_{r}$ and

$$
\Delta C=C_{s}-C_{r}=C_{0}-2 C_{r} .
$$

Combining (1), (2), and (3), we have

$$
P \mathrm{~d} t=\frac{(l * V / S) \mathrm{d} C_{r}}{\left(C_{0}-2 C_{r}\right)} .
$$

After integration,

$$
P\left(t-t_{L}\right)=\left(l * \frac{V}{2 S}\right) \ln \left[\frac{C_{0}}{\left(C_{0}-2 C_{r}\right)}\right] .
$$

This equation shows that, after an induction period $\left(t_{L}\right)$, which can reach several hours, the term $-\ln \left(C_{0}-2 C_{r}\right)$ should be a linear function of time $t$.

The slope $(a)$ of this line allows calculating the permeability, using

$$
P=a \times \frac{V l}{2 S}
$$

The initial flux $J_{0}$ can be calculated from the permeability $P$ according to the following:

$$
J_{0}=P \times \frac{C_{0}}{l} .
$$

The experience end is achieved when a dynamic equilibrium is established between the two compartments, with $C_{s}=C_{r}=$ $C_{0} / 2$ and diffusion rates being equal in both directions.
3.2. Thermodynamic Model and Determination of Microscopic Parameters. Transport of a substrate $S$ depends on the formation and dissociation of the complex carrier-substrate (TS) at solution-membrane interfaces. It should be noted that the carrier $T$ is insoluble in aqueous phases and the substrate $S$ is insoluble in the membrane organic phase. The formationdissociation equilibrium of the complex (TS) is

$$
T_{\text {org }}+S_{\text {aq }} \Longleftrightarrow T S_{\text {org }},
$$

where org and aq are, respectively, the membrane organic phase and the aqueous source and receiving phases. Concentration $[T S]_{i}$ of complex at the membrane interface is governed by the law of mass action according to the following:

$$
[T S]_{i}=K_{\text {ass }}[T]_{i}[S]_{i},
$$

where $K_{\text {ass }}$ is the association constant on the complex (TS) and is the equilibrium constant of this heterogeneous reaction at the interface feed phase-membrane; $[T]_{i}$ is the carrier concentration at the interface membrane-feed phase; and $[S]_{i}$ is the substrate concentration in the source phase at the membrane interface.

In the rate-determining step, the flux $J$ is determined by (10), derived from Fick's first law, which assumes that the complex concentration [ST] is almost zero at the interface membrane-receiving phase (dissociation of the complex):

$$
J=\left(\frac{D^{*}}{l}\right) \times[T S]_{i} .
$$

where $D^{*}$ is the apparent diffusion coefficient and $l$ is the membrane thickness.

However, at the interface source phase-membrane, $[T S]_{i} \ll[S]_{i}$ (excess of substrate relative to the carrier) and the concentration $[S]_{i}$ is equal to the substrate concentration $[S]_{t}$ at time $t$ and thus $[S]_{i}=[S]_{t}$. The total carrier concentration $[T]_{0}$ immobilized in the membrane is constant, and it is equal to the sum of the concentrations $[T]_{i}$ and $[T S]_{i}$.

$$
\begin{aligned}
{[T]_{0} } & =[T]_{i}+[T S]_{i} \\
& =[T S]_{i} \cdot\left[\frac{\left(1+K_{\mathrm{ass}} \cdot[S]_{i}\right)}{K_{\mathrm{ass}}} \cdot[S]_{i}\right], \\
{[T S]_{i} } & =[T]_{0} \cdot K_{\mathrm{ass}} \cdot \frac{[S]_{i}}{\left(1+K_{\mathrm{ass}} \cdot[S]_{i}\right)} .
\end{aligned}
$$

But, in the initial conditions, we operate with an excess of substrate relative to the carrier and at the interface feed phasemembrane, $[S]_{i}=[S]_{0}=C_{0}$. This allows to write the 
expression for the initial flux $J_{0}$ according to $[T]_{0}$ and $C_{0}((10)$ and (12)):

$$
J=\left(\frac{D^{*}}{l}\right) \times\left([T]_{0} \cdot K_{\mathrm{ass}} \cdot \frac{[S]_{i}}{\left(1+K_{\mathrm{ass}} \cdot[S]_{i}\right)}\right) .
$$

or

$$
J_{0}=\left(\frac{D^{*}}{l}\right) \times\left([T]_{0} \cdot K_{\mathrm{ass}} \cdot \frac{C_{0}}{\left(1+K_{\mathrm{ass}} \cdot C_{0}\right)}\right)
$$

This expression is used to calculate the membrane permeability $P$ according to $[T]_{0}, C_{0}$, and constant $K_{\text {ass }}$ :

$$
P=J_{0} \cdot \frac{l}{C_{0}}=\left(D^{*}\right) \times\left([T]_{0} \cdot \frac{K_{\text {ass }}}{\left(1+K_{\text {ass }} \cdot C_{0}\right)}\right) .
$$

These relationships indicate that the evolution of macroscopic parameters $J_{0}$ and $P$ is proportional to the initial substrate concentration $C_{0}$ and it is of Michaelis-Menten type, since, at high substrate concentrations, these two parameters are the limit values by saturation phenomenon of the carrier.

To determine the microscopic parameters $D^{*}$ and $K_{\text {ass }}$, we linearized the expression in (16) as Lineweaver-Burk straights $1 / J_{0}=f\left(1 / C_{0}\right)$.

$$
\frac{1}{J_{0}}=\left(\frac{l}{D^{*}}\right) \times\left[\left(\frac{1}{[T]_{0}} \cdot K_{\text {ass }}\right) \cdot\left(\frac{1}{C_{0}}\right)+\left(\frac{1}{[T]_{0}}\right)\right]
$$

and therefore

$$
\begin{aligned}
K_{\text {ass }} & =\frac{\operatorname{intercept}(O O)}{\operatorname{slope}(p)}, \\
D^{*} & =\left(\frac{l}{O O}\right) \cdot\left(\frac{1}{[T]_{0}}\right) .
\end{aligned}
$$

3.3. Determination of Activation Parameters. Studies relating to the facilitated extraction process of ions across membranes $[25,26]$ indicate that the initial flux is related to temperature factor by Arrhenius law, according to the following relationship:

$$
J_{i}(T)=A_{j} \exp \left(-\frac{E_{a}}{R T}\right),
$$

where $R$ is the gas constant $\left(8.314 \mathrm{~J} \cdot \mathrm{mol}^{-1} \cdot \mathrm{K}^{-1}\right), A_{j}$ is a constant (preexponential factor), and $E_{a}$ is the transition state activation energy on the formation-dissociation reaction of entity (TS) at the membrane interfaces and in the SLM organic phase, during the migration of the substrate through the membrane, which is the rate-determining step relative to the apparent diffusion of the complex (TS). After linearization, we get

$$
\ln J_{i}=\frac{-E_{a}}{R} \times \frac{1}{T}+\ln A_{j} .
$$

Thus the terms of activation energy $\left(E_{a}\right)$ and preexponential factor $\left(A_{j}\right)$ are determined from the slope and intercept for the linear function $\ln \left(J_{i}\right)$ versus $(1 / T)$. According to the activated complex theory (Eyring theory), we can calculate the activation parameters, enthalpy $\Delta H^{\neq}$, and entropy $\Delta S^{\neq}$, according to the expressions in

$$
\begin{aligned}
\Delta H^{\neq} & =E_{a}-2500\left(\mathrm{~J} \cdot \mathrm{mol}^{-1}\right), \\
\Delta S^{\neq} & =R\left(\ln A_{j}-30,46\right)\left(\mathrm{J} \cdot \mathrm{K}^{-1} \cdot \mathrm{mol}^{-1}\right)
\end{aligned}
$$

at $298^{\circ} \mathrm{K}$.

\section{Results and Discussion}

4.1. Macroscopic Parameters $P$ and $J_{0}$. In the same experimental conditions, using each of the three prepared membranes (MLSs) with one of the agents MC, RESO, or TOA in the same concentration $\left([T]_{0}=0.01 \mathrm{M}\right)$ facilitated extraction of $\mathrm{VO}_{2}{ }^{+}$ions that was carried out for different initial concentrations $C_{0}(0.0125-0.100 \mathrm{M})$ at the same temperature $293 \mathrm{~K}$. Proposed kinetic model for this phenomenon in which the diffusion of the complex carrier-substrate (TS) is considered the rate-determining step indicates that the evolution of the term $-\ln \left(C_{0}-2 C_{r}\right)$ must be linear in function of time (see (5)). Indeed, the experimental results verify the model and allow obtaining the straight line segments shown by graphs of Figures 6 and 7.

The slopes calculated from these lines are used to determine the permeability values $(P)$ of the used membranes with respect to $\mathrm{VO}_{2}{ }^{+}$ions for different tested solutions (see (6)), while the initial flux values $\left(J_{0}\right)$ of the substrate through the used SLMs are calculated using (7). Table 2 summarizes all results for the three membranes at temperature $293 \mathrm{~K}$.

All these experimental results indicate that the permeability $P$ of the used SLM varies inversely with the initial concentration $C_{0}$ of $\mathrm{VO}_{2}{ }^{+}$ions, and an increase in substrate concentration results in a decrease in permeability. However, the initial flux values $J_{0}$ of these ions through each of studied SLMs increase as the initial concentration $C_{0}$ of the substrate [27-29]. On the other hand, we observe that the values of permeabilities $P$ and initial fluxes $J_{0}$ relative facilitated extraction of $\mathrm{VO}_{2}{ }^{+}$ions, using both SLMs containing, respectively, methyl cholate (MC) and resorcinarene (RESO) as extractive agents are slightly near, while the use of the SLM containing trioctylamine (TOA) as extractive agent provides relatively high values for these two parameters $P$ and $J_{0}$, in the same experimental conditions and the same temperature.

4.2. Microscopic Parameters $D^{*}$ and $K_{\text {ass. }}$. To verify the proposed mechanism for this facilitated extraction phenomenon of the $\mathrm{VO}_{2}{ }^{+}$ions by prepared SLMs and determine the microscopic parameters, apparent coefficients $D^{*}$, and association constants $K_{\text {ass }}$, we traced the Lineweaver-Burk lines $\left(1 / J_{0}=\right.$ $f\left(1 / C_{0}\right)$ ) provided by (16), from the experimental results for the three used SLMs. The obtained line segments are shown by the graph in Figure 8 .

The obtained straight lines clearly indicate that the proposed mechanism for this phenomenon is verified, and there is formation entity (ST) of composition (1/1), by association "substrate-extractive agent" in the organic phase of used SLM. The migration of this entity through this phase is the 


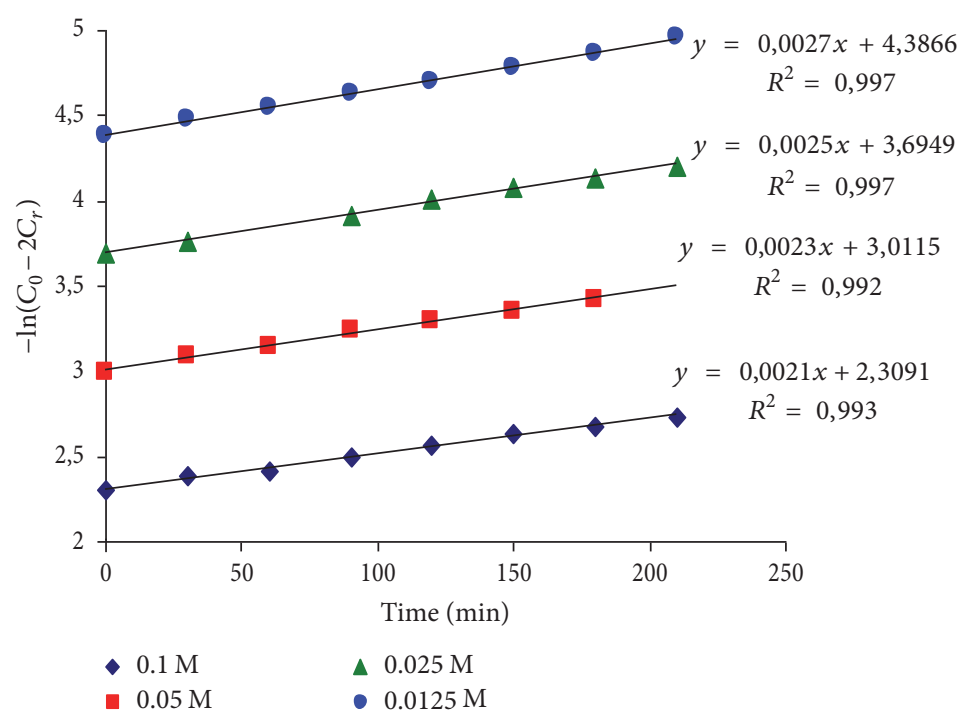

FIGURE 6: Evolution of the term $-\ln \left(C_{0}-2 C_{r}\right)$ versus time for facilitated extraction of $\mathrm{VO}_{2}{ }^{+}$ions by SLM containing extractive agent RESO. $\left[\mathrm{H}_{3} \mathrm{O}^{+}\right]=1 \mathrm{M},[\mathrm{RESO}]=10^{-2} \mathrm{M}$, and $T=293 \mathrm{~K}$.

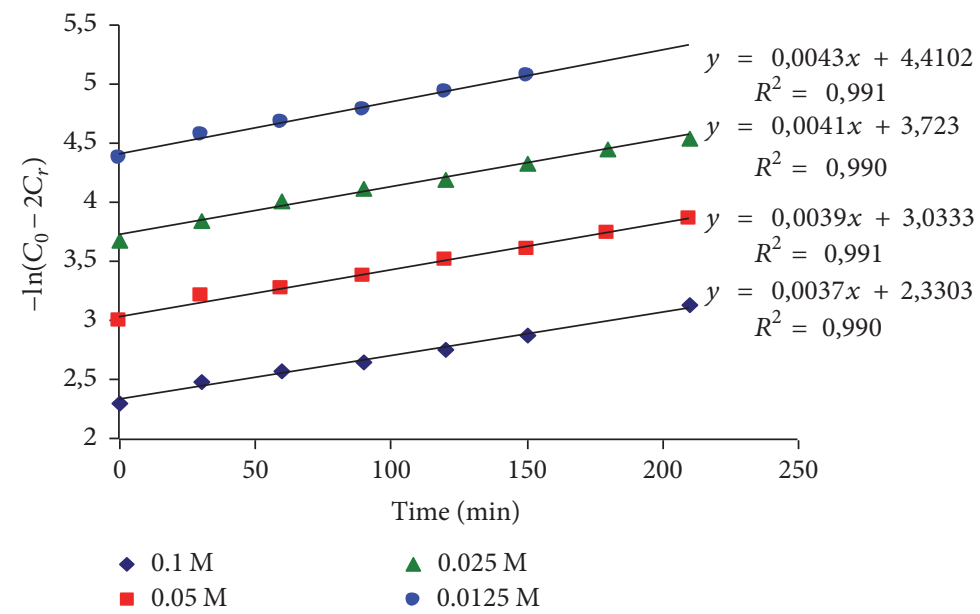

FIGURE 7: Evolution of the term $-\ln \left(C_{0}-2 C_{r}\right)$ versus time for facilitated extraction of $\mathrm{VO}_{2}{ }^{+}$ions by SLM containing extractive agent TOA. $\left[\mathrm{H}_{3} \mathrm{O}^{+}\right]=1 \mathrm{M},[\mathrm{TOA}]=10^{-2} \mathrm{M}$, and $T=293 \mathrm{~K}$.

rate-determining step of the mechanism for the facilitated extraction of $\mathrm{VO}_{2}{ }^{+}$ions. Slopes $(p)$ and intercepts $(O O)$ were calculated from these lines and using the expressions in (16); the apparent coefficients $D^{*}$ and the association constants $K_{\text {ass }}$ were determined. The obtained results for the used membranes are summarized in Table 3 and the histogram in Figure 9 shows that these two microscopic parameters vary inversely. This result indicates that a high stability of entity $(S T)$ formed in the SLM organic phase results in a low diffusion of this entity and conversely.

The values of permeability $P$, initial flux $J_{0}$, (Table 2), association constant $K_{\text {ass }}$, and apparent diffusion coefficient $D^{*}$ (Table 3), relating to this facilitated extraction phenomenon of $\mathrm{VO}_{2}{ }^{+}$ions, clearly show that, for the same concentration of the extractive agent $(0.01 \mathrm{M})$ and at the same temperature $(293 \mathrm{~K})$, the facilitated extraction of the substrate $\left(\mathrm{VO}_{2}{ }^{+}\right)$is more efficient through SLM containing trioctylamine (TOA) as extractive agent, compared with two other investigated membranes, containing, respectively, methyl cholate (MC) and resorcinarene (RESO). These results clearly show that the value of association constant $K_{\text {ass }}$ depends on the nature of association site carried by each of the extractive agents, as well as the reverse evolution of $K_{\text {ass }}$ and $D^{*}$ parameters, indicates that the movement of $\mathrm{VO}_{2}{ }^{+}$ions in the membrane organic phase cannot be a pure diffusion movement, but it takes place by successive jumps of the substrate $\left(\mathrm{VO}_{2}{ }^{+}\right)$from one site to another of the extractive agent in successive and reversible reactions (association/dissociation).

4.3. Influence of the Temperature Factor. Under the same experimental conditions and using membranes, respectively. MLS-RESO, SLM-MC, and SLM-TOA, we performed experiments to the facilitated extraction of $\mathrm{VO}_{2}{ }^{+}$ions in solutions of $C_{0}$ concentrations ranging from 0.0125 to $0.1 \mathrm{M}$ and at 
TABLE 2: The values of macroscopic parameters $\left(P\right.$ and $\left.J_{0}\right)$ on the facilitated extraction of $\mathrm{VO}_{2}{ }^{+}$ions by the three developed SLMs.

\begin{tabular}{|c|c|c|c|c|c|c|}
\hline \multirow{2}{*}{$\begin{array}{l}C_{0} \text { concentration } \\
\left(\mathrm{mol} \mathrm{L}^{-1}\right)\end{array}$} & \multicolumn{3}{|c|}{ Permeability $P\left(10^{7} \mathrm{~cm}^{2} \mathrm{~s}^{-1}\right)$} & \multicolumn{3}{|c|}{ Initial Flux $J_{0}\left(10^{5} \mathrm{mmol} \mathrm{s}^{-1} \mathrm{~cm}^{-2}\right)$} \\
\hline & RESO & MC & TOA & RESO & MC & TOA \\
\hline 0.1 & 13.37 & 17.28 & 23.56 & 1.33 & 1.72 & 2.35 \\
\hline 0.05 & 14.64 & 18.22 & 24.84 & 0.73 & 0.91 & 1.24 \\
\hline 0.025 & 15.92 & 20.27 & 26.11 & 0.39 & 0.50 & 0.65 \\
\hline 0.0125 & 17.19 & 21.29 & 27.38 & 0.21 & 0.26 & 0.34 \\
\hline
\end{tabular}

$[$ RESO $]=[\mathrm{MC}]=[\mathrm{TOA}]=10^{-2} \mathrm{M}\left[\mathrm{H}_{3} \mathrm{O}^{+}\right]=1 \mathrm{M}$, and $T=293 \mathrm{~K}$.

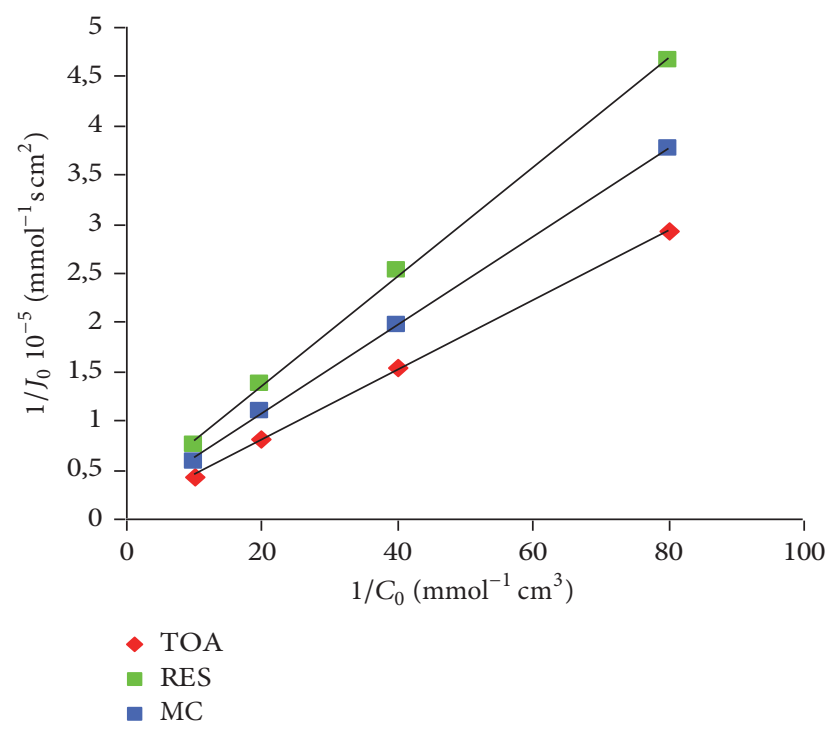

Figure 8: The Lineweaver-Burk representation $1 / J_{0}=f\left(1 / C_{0}\right)$ for facilitated extraction of $\mathrm{VO}_{2}{ }^{+}$ions by adopted SLMs. [RESO] $=$ $[\mathrm{MC}]=[\mathrm{TOA}]=10^{-2} \mathrm{M},\left[\mathrm{H}_{3} \mathrm{O}^{+}\right]=1 \mathrm{M}$, and $\mathrm{T}=293 \mathrm{~K}$.

TABLE 3: Values of microscopic parameters $\left(D^{*}\right.$ and $\left.K_{\text {ass }}\right)$ for facilitated extraction of $\mathrm{VO}_{2}{ }^{+}$ions.

\begin{tabular}{lccc}
\hline Extractive agent & RESO & MC & TOA \\
\hline$D^{*} 10^{5}\left(\mathrm{~cm}^{2} \cdot \mathrm{s}^{-1}\right)$ & 4.19 & 6.15 & 11.50 \\
$K_{\text {ass }}\left(\mathrm{L} \cdot \mathrm{mol}^{-1}\right)$ & 4.29 & 3.60 & 2.48 \\
\hline
\end{tabular}

$[$ RESO $]=[\mathrm{MC}]=[\mathrm{TOA}]=10^{-2} \mathrm{M},\left[\mathrm{H}_{3} \mathrm{O}^{+}\right]=1 \mathrm{M}$, and $T=293 \mathrm{~K}$.

temperatures 293, 298, and $303^{\circ} \mathrm{K}$. Graphs in Figures 10 and 11 represent the straight lines relating to the evolution of the term $-\ln \left(C_{0}-2 C_{r}\right)$ with time provided by kinetic model, for different studied temperatures, at $C_{0}=0.10 \mathrm{M}$, and for adopted membranes SLM-TOA and SLM-RESO.

The slopes calculated from obtained lines for the different experiments were used to calculate according to the expressions in (6) and (7), the values of permeabilities $P$, and initial fluxes $J_{0}$, relative to this facilitated extraction phenomenon of $\mathrm{VO}_{2}{ }^{+}$ions through the adopted membranes. For the different studied temperatures, all obtained results are summarized in Table 4.

These results confirm that the permeability $P$ and the initial flux $J_{0}$ parameters vary inversely and with the initial concentration $\mathrm{C}_{0}$ of $\mathrm{VO}_{2}{ }^{+}$ions $[18,19]$. They indicate

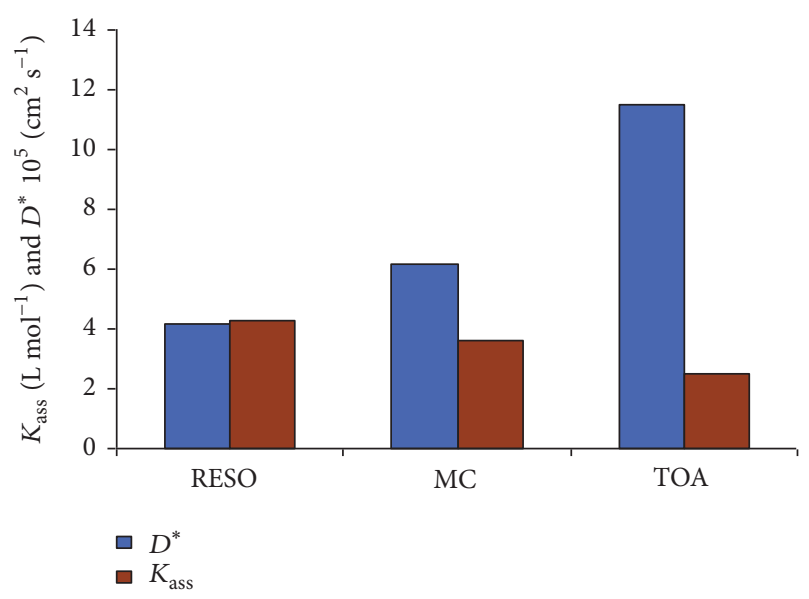

FIGURE 9: Microscopic parameters evolution for facilitated extraction phenomenon of $\mathrm{VO}_{2}{ }^{+}$ions.

clear influence of temperature factor on the values of these parameters and therefore an increase in the membrane performances, with an excellent performance of SLM-TOA membrane relative to other adopted SLMs.

To confirm the previous results and to study temperature factor influence on the evolution of microscopic parameters $D^{*}$ and $K_{\text {ass }}$, we traced the Lineweaver-Burk lines, $1 / J_{0}=$ $f\left(1 / C_{0}\right)$, and the obtained line segments are represented by the graphs in Figures 12 and 13, for two adopted membranes SLM-RESO and SLM-MC.

Slopes $(p)$ and intercepts (oo) determined from different Lineweaver-Burk straight lines (Figures 12 and 13) were used to calculate the values of parameters $D^{*}$ and $K_{\text {ass }}$ according to the terms in (16). The obtained results are summarized in Table 5 and confirm the inverse evolution of these microscopic parameters, and the temperature factor influence, in fact, an increase in the temperature causes a decrease in the value of $K_{\text {ass }}$ and increased the coefficient $D^{*}$ and therefore an improvement of the adopted membrane performance.

For the three adopted membranes, the results indicate a clear influence of temperature factor on the evolution of $K_{\text {ass }}$ and $D^{*}$ parameters, and an increase in temperature results in a weak association of substrate $\left(\mathrm{VO}_{2}{ }^{+}\right)$with the extractive agent, so fast jumps of substrate from one site to another of extractive agent, and a good substrate diffusion through the membrane. These results also show that microscopic parameters $K_{\text {ass }}$ and $D^{*}$ are specific for the pair (substrate, 


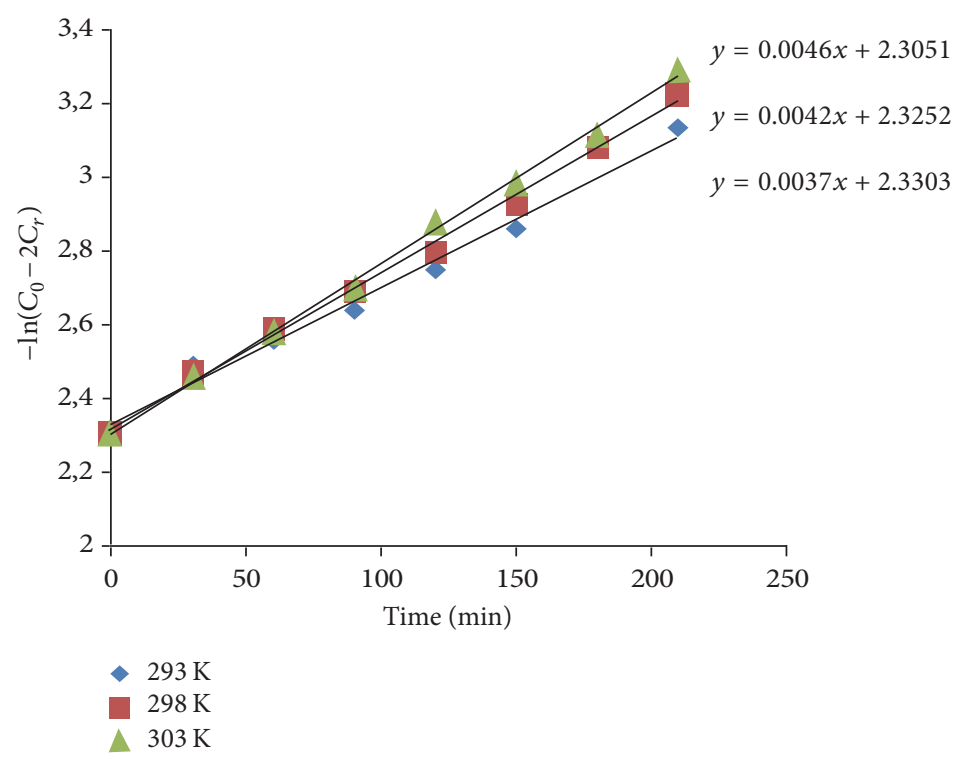

Figure 10: $-\ln \left(C_{0}-2 C_{r}\right)$ term evolution versus temperature for the facilitated extraction of $\mathrm{VO}_{2}{ }^{+}$ions through membrane SLM-TOA. [H $\left.\mathrm{H}_{3} \mathrm{O}^{+}\right]$ $=1 \mathrm{M},[\mathrm{TOA}]=10^{-2} \mathrm{M},\left[\mathrm{VO}_{2}^{+}\right]=0.1 \mathrm{M}$.

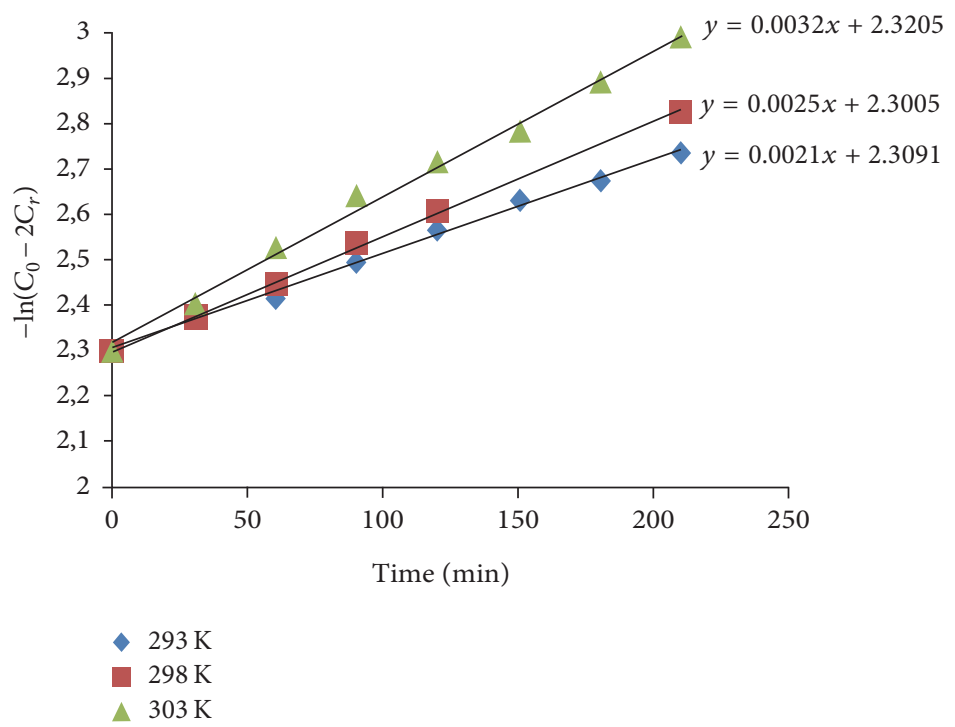

Figure 11: Temperature effect on $-\ln \left(C_{0}-2 C_{r}\right)$ term evolution versus time, for the facilitated extraction of $\mathrm{VO}_{2}{ }^{+}$ions by membrane SLMRESO. $\left[\mathrm{H}_{3} \mathrm{O}^{+}\right]=1 \mathrm{M},[\mathrm{RESO}]=10^{-2} \mathrm{M}\left[\mathrm{VO}_{2}{ }^{+}\right]=0.1 \mathrm{M}$.

extractive agent), and SLM-TOA membrane remains the most effective for this facilitated extraction process of $\mathrm{VO}_{2}{ }^{+}$ ions.

4.4. Activation Parameters $E_{a}, \Delta H^{\neq}$, and $\Delta S^{\neq}$. To examine the influence of energetic and associative terms on the mechanism for the facilitated extraction process of $\mathrm{VO}_{2}{ }^{+}$ ions, we plotted the function $\ln \left(J_{0 \text { moy }}\right)=f(1 / T)$ provided by Arrhenius relationship (see (19)). For adopted SLMs, the line segments obtained at studied temperatures are represented by the graph in Figure 14.

The slopes $(p)$ and intercepts (oo) calculated from straight lines represented by the graph in Figure 14 were used to determine according to the expressions in (20) and the values of activation parameters, energy $E_{a}$, enthalpy $\Delta H^{\neq}$, and entropy $\Delta S^{\neq}$, related to the transition states of association/dissociation reactions of substrate $\left(\mathrm{VO}_{2}{ }^{+}\right)$with each of extractive agents (TOA, MC, or RESO). All obtained results for these parameters are summarized in Table 6,

These results clearly indicate that the transition states related to association/dissociation reactions of substrate with the extractive agent are highly ordered states and require small amounts of energy. The analysis of the results shows that the facilitated extraction process $\mathrm{VO}_{2}{ }^{+}$ions is a phenomenon governed by a structural term related to the nature and the structure of the interaction site of each extractive agents; then 
TABLE 4: Temperature factor influence on the evolution of macroscopic parameters $P$ and $J_{0}$.

\begin{tabular}{|c|c|c|c|c|c|c|c|}
\hline \multirow[t]{2}{*}{ Extractive agent } & \multirow[t]{2}{*}{$C_{0} \mathrm{~mol} \mathrm{~L}^{-1}$} & \multicolumn{3}{|c|}{$P \cdot 10^{7} \mathrm{~cm}^{2} \mathrm{~s}^{-1}$} & \multicolumn{3}{|c|}{$J_{0} \cdot 10^{5} \mathrm{mmol} \mathrm{s}^{-1} \mathrm{~cm}^{-2}$} \\
\hline & & $293 \mathrm{~K}$ & $298 \mathrm{~K}$ & $303 \mathrm{~K}$ & $293 \mathrm{~K}$ & $298 \mathrm{~K}$ & $303 \mathrm{~K}$ \\
\hline \multirow{5}{*}{ RESO } & 0.1 & 13.37 & 15.92 & 20.38 & 1.33 & 1.59 & 2.03 \\
\hline & 0.05 & 14.64 & 17.19 & 21.65 & 0.73 & 0.85 & 1.08 \\
\hline & 0.025 & 15.92 & 18.47 & 22.92 & 0.39 & 0.46 & 0.57 \\
\hline & 0.0125 & 17.19 & 19.74 & 24.20 & 0.21 & 0.24 & 0.30 \\
\hline & & $288 \mathrm{~K}$ & $293 \mathrm{~K}$ & $303 \mathrm{~K}$ & $288 \mathrm{~K}$ & $293 \mathrm{~K}$ & $303 \mathrm{~K}$ \\
\hline \multirow{5}{*}{ MC } & 0.1 & 14.43 & 17.28 & 24.71 & 1.44 & 1.72 & 2.47 \\
\hline & 0.05 & 16.47 & 18.22 & 25.95 & 0.82 & 0.91 & 1.29 \\
\hline & 0.025 & 17.57 & 20.27 & 28.43 & 0.43 & 0.50 & 0.71 \\
\hline & 0.0125 & 18.66 & 21.29 & 29.89 & 0.23 & 0.26 & 0.37 \\
\hline & & $293 \mathrm{~K}$ & $298 \mathrm{~K}$ & $303 \mathrm{~K}$ & $293 \mathrm{~K}$ & $298 \mathrm{~K}$ & $303 \mathrm{~K}$ \\
\hline \multirow{4}{*}{ TOA } & 0.1 & 23.56 & 26.75 & 29.30 & 2.35 & 2.67 & 2.92 \\
\hline & 0.05 & 24.84 & 28.02 & 30.57 & 1.24 & 1.40 & 1.52 \\
\hline & 0.025 & 26.11 & 28.62 & 31.84 & 0.65 & 0.71 & 0.79 \\
\hline & 0.0125 & 27.38 & 30.57 & 33.12 & 0.34 & 0.38 & 0.41 \\
\hline
\end{tabular}

$[\mathrm{RESO}]=[\mathrm{MC}]=[\mathrm{TOA}]=10^{-2} \mathrm{M}$.

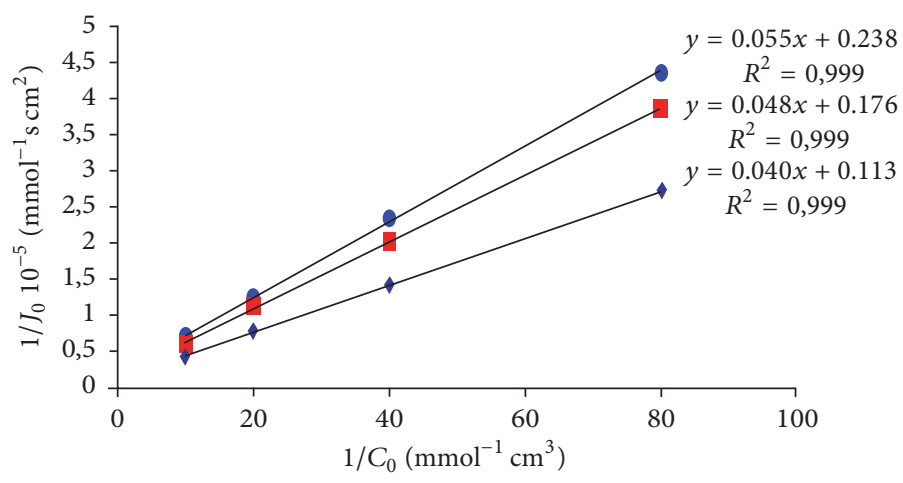

- $293 \mathrm{~K}$

- $298 \mathrm{~K}$

- $303 \mathrm{~K}$

FIGURE 12: Lineweaver-Burk lines for the facilitated extraction of $\mathrm{VO}_{2}{ }^{+}$ions by SLM-RESO membrane, for different values of temperature. $\left[\mathrm{H}_{3} \mathrm{O}^{+}\right]=1 \mathrm{M},[\mathrm{RESO}]=10^{-2} \mathrm{M}$.

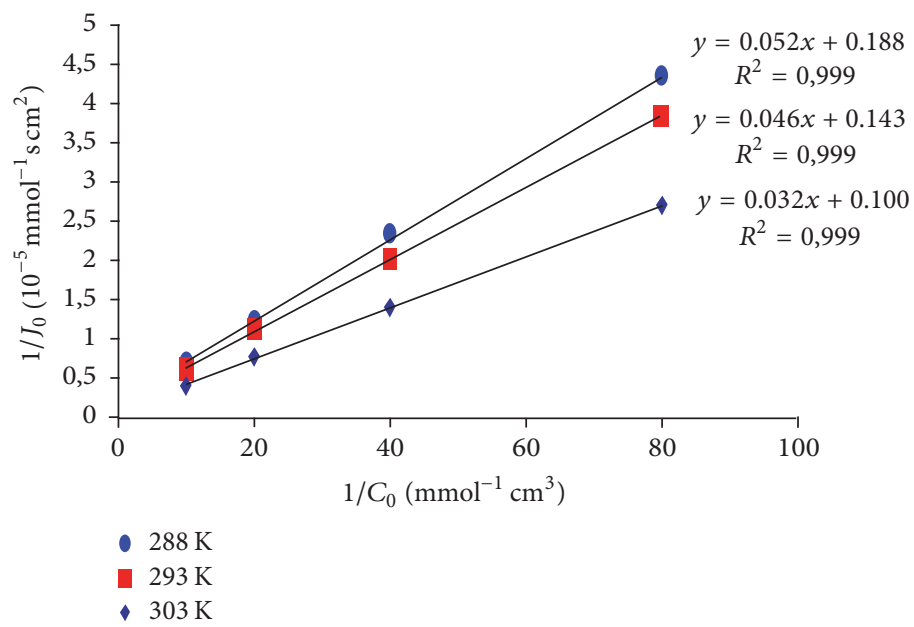

FIGURE 13: Lineweaver-Burk straight lines relating to the influence of temperature on the microscopic parameters for extracting $\mathrm{VO}_{2}{ }^{+}$ions by SLM-MC membrane. $\left[\mathrm{H}_{3} \mathrm{O}^{+}\right]=1 \mathrm{M},[\mathrm{MC}]=10^{-2} \mathrm{M}$. 
TABLE 5: Temperature factor influence on the values of $K_{\text {ass }}$ and $D^{*}$ for the facilitated extraction phenomenon of $\mathrm{VO}_{2}{ }^{+}$ions.

\begin{tabular}{lccc}
\hline Extractive agent & $T(\mathrm{~K})$ & $D^{*} \cdot 10^{5}\left(\mathrm{~cm}^{2} \cdot \mathrm{s}^{-1}\right)$ & $K_{\mathrm{ass}}\left(\mathrm{L} \cdot \mathrm{mol}^{-1}\right)$ \\
\hline \multirow{3}{*}{ RESO } & $\mathbf{2 9 3}$ & 4.19 & 4.29 \\
& 298 & 5.67 & 3.61 \\
\hline \multirow{3}{*}{ MC } & 303 & 8.80 & 2.83 \\
& 288 & 5.19 & 3.75 \\
& 293 & $\mathbf{6 . 1 5}$ & 3.60 \\
TOA & 303 & 9.42 & 3.29 \\
& 293 & 11.50 & 2.48 \\
& 298 & 14.08 & 2.29 \\
\end{tabular}

[Extractive agent $]=0.01 \mathrm{M}$ and $\left[\mathrm{H}_{3} \mathrm{O}^{+}\right]=1 \mathrm{M}$.

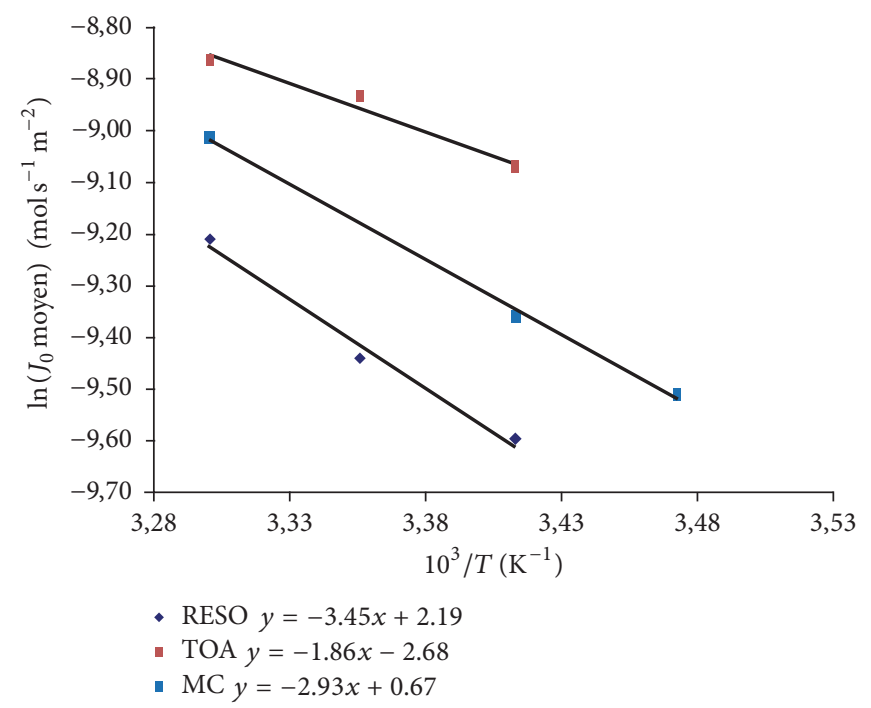

FIGURE 14: The representation of $\ln \left(J_{0 \text { moy }}\right)=f(1 / T)$ function on the facilitated extraction phenomenon of $\mathrm{VO}_{2}{ }^{+}$ions by three membranes: SLM-RESO (-MC) and (-TOA).

the influence of energetic term is negligible. On the other hand, recent studies $[5,6,30,31]$ and this analysis confirm previous results which indicate that the substrate movement across each of the developed membranes cannot be a pure diffusion movement (way $A$ ), but it takes place by successive jumps of one site to an another of used extractive agent, via interaction reactions of $\mathrm{VO}_{2}{ }^{+}$ions with the extractive agent according to the way $B$ indicated by the diagram in Figure 15.

\section{Conclusion}

Three supported liquid membranes (SLMs) were prepared with same polymer support (PVDF), same organic phase (toluene), and three different extractive agents (TOA, MC, and RESO). These three SLMs were adopted for the facilitated extraction process of $\mathrm{VO}_{2}{ }^{+}$ions from concentrated acidic environments. All experimental results verify the proposed kinetic model, which was used to determine the macroscopic parameters permeability $P$ and initial flux $J_{0}$ relating to each adopted membranes. The obtained results show that prepared SLMs are highly permeable for the extraction process of
$\mathrm{VO}_{2}{ }^{+}$ions. To better understand this facilitated extraction phenomenon by this liquid membrane type, we developed a thermodynamic model based on the formation of an entity (ST) by association of substrate with the extractive agent at membrane interface and the migration of this formed entity through membrane organic phase. This model was verified by experimental results, which helped to determine the microscopic parameters, association constant $K_{\text {ass }}$, and apparent diffusion coefficient $D^{*}$, related to the formation of the entity $(S T)$ and its diffusion through membrane organic phase. The low values of association constants $K_{\text {ass }}$ and the high values of apparent coefficients $D^{*}$ perfectly explain the large permeabilities and high fluxes obtained for this facilitated extraction process of $\mathrm{VO}_{2}{ }^{+}$ions by prepared SLMs. Indeed, the parameters $K_{\text {ass }}$ and $D^{*}$ vary inversely, and the results indicate that very low values of constant $K_{\text {ass }}$ result in higher values of apparent coefficients $D^{*}$; this important result shows that these high values of coefficients $D^{*}$ certainly do not reflect a pure diffusion movement of the entity (ST) through adopted SLM organic phase. Some recent studies on the facilitated extraction process of metal ions or organic 
TABLE 6: All values of microscopic parameters $K_{\text {ass }}$ and $D^{*}$ and activation parameters $E_{a}, \Delta H^{\neq}$, and $\Delta S^{\neq}$for facilitated extraction process of $\mathrm{VO}_{2}{ }^{+}$ions.

\begin{tabular}{|c|c|c|c|c|c|c|}
\hline Extractive agent & $T(\mathrm{~K})$ & $\begin{array}{l}D^{*} \cdot 10^{5} \\
\left(\mathrm{~cm}^{2} \cdot \mathrm{s}^{-1}\right)\end{array}$ & $\begin{array}{c}K_{\text {ass }} \\
\left(\mathrm{L} \cdot \mathrm{mol}^{-1}\right)\end{array}$ & $\begin{array}{c}E_{a} \\
\left(\mathrm{~J} \cdot \mathrm{mol}^{-1}\right)\end{array}$ & $\begin{array}{c}\Delta H^{\neq} \\
\left(\mathrm{J} \cdot \mathrm{mol}^{-1}\right)\end{array}$ & $\begin{array}{c}\Delta S^{\neq} \\
\left(\mathrm{J} \cdot \mathrm{K}^{-1} \cdot \mathrm{mol}^{-1}\right)\end{array}$ \\
\hline \multirow{3}{*}{ RESO } & 293 & 4.19 & 4.29 & \multirow{3}{*}{28767.57} & \multirow{3}{*}{26291.19} & \multirow{3}{*}{-232.85} \\
\hline & 298 & 5.67 & 3.61 & & & \\
\hline & 303 & 8.80 & 2.83 & & & \\
\hline \multirow{3}{*}{ MC } & 288 & 5.19 & 3.75 & \multirow{3}{*}{24469.63} & \multirow{3}{*}{21969.63} & \multirow{3}{*}{-235.84} \\
\hline & 293 & 6.15 & 3.60 & & & \\
\hline & 303 & 9.42 & 3.29 & & & \\
\hline \multirow{3}{*}{ TOA } & 293 & 11.50 & 2.48 & \multirow{3}{*}{15531.39} & \multirow{3}{*}{13055.01} & \multirow{3}{*}{-275.39} \\
\hline & 298 & 14.08 & 2.29 & & & \\
\hline & 303 & 17.24 & 1.97 & & & \\
\hline
\end{tabular}

$[\mathrm{RESO}]=[\mathrm{MC}]=[\mathrm{TOA}]=10^{-2} \mathrm{M}$.

(A)

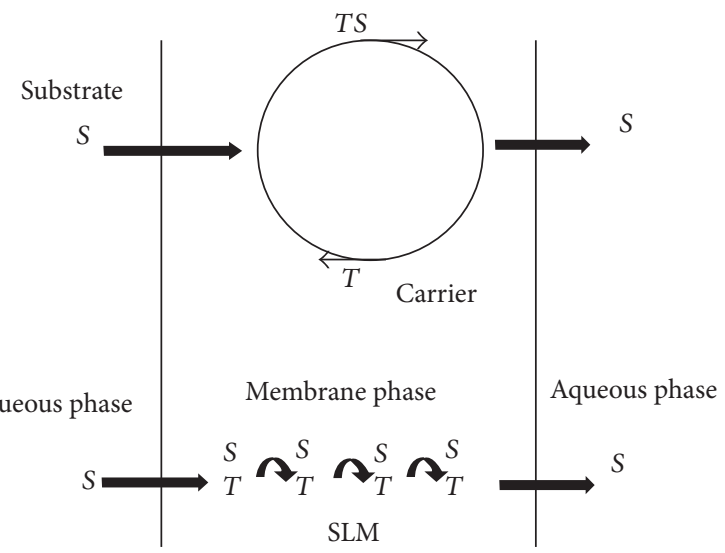

FIgURE 15: Possible movements of substrate across the organic phases of SLM membranes: (A) pure diffusion movement (low values of $D^{*}$ ), (B) movement in successive jumps (high values of $\left.D^{*}\right)$.

molecules by the same type of membranes clearly confirm the high values of the coefficients $D^{*}$ and explain this result by the movement nature of the substrate $S$ during its passage from the source aqueous phase to the receiving aqueous phase, through the membrane organic phase. Indeed, the results clearly show that the mechanism for this facilitated extraction process of $\mathrm{VO}_{2}{ }^{+}$ions is a mechanism performed by successive jumps of substrate $S$ from one site to another of extractive agent movable in the membrane organic phase. On the other hand, studies on the temperature factor influence indicated a clear evolution of all parameters for this phenomenon, and an increase in temperature results in a decrease in the association constant values $\left(K_{\text {ass }}\right)$ and an increase in parameter values of $D^{*}, P$, and $J_{0}$ and improved performance of the adopted SLMs. The results confirmed the proposed mechanism for this facilitated extraction process, and an increase in the temperature factor disadvantage interactions between substrate $S$ and the used extractive agent $T\left(K_{\text {ass }}\right.$ decreases) facilitates the phenomenon of substrate jumps from one site to another and therefore rapid passage $\left(D^{*}\right.$ increases) of $\mathrm{VO}_{2}{ }^{+}$ions through the membrane organic phase.

\section{Abbreviations}

a: $\quad$ Slope of the plot $-\ln \left(C_{0}-2 C_{r}\right)=f(t)$

$C_{0}$ : Initial concentration of $\mathrm{VO}_{2}^{+}$ions in the feed phase $\left(\mathrm{mol} \cdot \mathrm{L}^{-1}\right)$

$C_{r}$ : Concentration of $\mathrm{VO}_{2}{ }^{+}$ions in the receiving phase $\left(\mathrm{mol} \cdot \mathrm{L}^{-1}\right)$

$C_{s}$ : Concentration of $\mathrm{VO}_{2}{ }^{+}$ions in the source phase $\left(\mathrm{mol} \cdot \mathrm{L}^{-1}\right)$

$P: \quad$ The membrane permeability ions $\left(\mathrm{cm}^{2} \cdot \mathrm{s}^{-1}\right)$

$J_{0}:$ Initial flux of $\mathrm{VO}_{2}{ }^{+}$ions $\left(\mathrm{mmol} \cdot \mathrm{cm}^{-2} \cdot \mathrm{s}^{-1}\right)$

$D^{*}$ : Apparent diffusion coefficient of the complex (TS) $\left(\mathrm{cm}^{2} \cdot \mathrm{s}^{-1}\right)$

$K_{\text {ass }}:$ Association constant of the complex (TS) $\left(\mathrm{L} \cdot \mathrm{mol}^{-1}\right)$

$l: \quad$ The membrane thickness ( $\mathrm{mm}$ or $\mu \mathrm{m}$ )

$S: \quad$ The membrane active area $\left(\mathrm{cm}^{2}\right)$

$[T]_{0}$ : Concentration of carrier in the membrane $\left(\mathrm{mol} \cdot \mathrm{L}^{-1}\right)$

[TS]: Concentration of the complex in the organic phase $\left(\mathrm{mol} \cdot \mathrm{L}^{-1}\right)$

$T: \quad$ Temperature (K)

$t: \quad$ Time (s)

$V: \quad$ Volume of the receiving compartment $\left(\mathrm{cm}^{3}\right)$.

\section{Conflicts of Interest}

The authors declare that they have no conflicts of interest.

\section{References}

[1] L. J. Lozano, C. Godínez, and F. J. Alguacil, "Facilitated transport of vanadium (V) by supported liquid membranes," Hydrometallurgy, vol. 80, no. 3, pp. 196-202, 2005.

[2] F. J. Alguacil and M. Alonso, "Transport of cadmium from a mixture of $\mathrm{HCl}$ and $\mathrm{H}_{3} \mathrm{PO}_{4}$ using phosphine oxides (Cyanex 921 and Cyanex 923) as carriers: the influence of the membrane 
diluents (Exxsol D100 and Solvesso 100)," Hydrometallurgy, vol. 74, no. 3-4, pp. 195-202, 2004.

[3] M. P. Elizalde, E. Garcia Pavon, A. Almela, and B. Menoyo, "Vanadium extraction from phosphoric acid solutions by LIX 860-I. Application to industrial phosphoric acid," Solvent Extraction and Ion Exchange, vol. 26, no. 3, pp. 180-191, 2008.

[4] M. Hor, A. Riad, A. Benjjar, L. Lebrun, and M. Hlaibi, “Technique of supported liquid membranes (SLMs) for the facilitated transport of vanadium ions $\left(\mathrm{VO}_{2}^{+}\right)$: parameters and mechanism on the transport process," Desalination, vol. 255, no. 1-3, pp. 188-195, 2010.

[5] H. Hassoune, T. Rhlalou, M. A. Frouji, C. Chappey, and J.F. Verchère, "Application of supported liquid membranes containing methyl cholate in cyclohexane for the carrier-mediated transport of sugars," Desalination, vol. 189, no. 1-3, pp. 31-42, 2006.

[6] K. Touaj, N. Tbeur, M. Hor, J.-F. Verchère, and M. Hlaibi, "A supported liquid membrane (SLM) with resorcinarene for facilitated transport of methyl glycopyranosides: parameters and mechanism relating to the transport," Journal of Membrane Science, vol. 337, no. 1-2, pp. 28-38, 2009.

[7] M. A. Chaudry, N. Bukhari, M. Mazhar, and F. Tazeen, "Vana$\operatorname{dium}(\mathrm{V})$ ions transport through tri-n-octyl amine cyclohexane supported liquid membranes," Separation and Purification Technology, vol. 54, no. 2, pp. 227-233, 2007.

[8] H. C. Visser, D. N. Reinhoudt, and F. De Jong, "Carriermediated transport through liquid membranes," Chemical Society Reviews, vol. 23, no. 2, pp. 75-81, 1994.

[9] M. T. A. Reis and J. M. R. Carvalho, "Modelling of zinc extraction from sulphate solutions with bis(2-ethylhexyl)thiophosphoric acid by emulsion liquid membranes," Journal of Membrane Science, vol. 237, no. 1-2, pp. 97-107, 2004.

[10] R. M. Izatt, J. D. Lamb, and R. L. Bruening, "Comparison of bulk, emulsion, thin sheet supported, and hollo fiber supported liquid membranes in macrocycle-mediated cation separations," Separation Science and Technology, vol. 23, no. 12-13, pp. 1645$1658,1988$.

[11] A. J. B. Kemperman, D. Bargeman, T. Van Den Boomgaard, and H. Strathmann, "Stability of supported liquid membranes: state of the art," Separation Science and Technology, vol. 31, no. 20, pp. 2733-2762, 1996.

[12] M. Mulder, Basic Principles of Membrane Technology, Springer, 1991.

[13] J. Å. Jönsson and L. Mathiasson, "Liquid membrane extraction in analytical sample preparation: I. Principles," TrAC-Trends in Analytical Chemistry, vol. 18, no. 5, pp. 318-325, 1999.

[14] H. Singh, S. L. Mishra, and R. Vijayalakshmi, "Uranium recovery from phosphoric acid by solvent extraction using a synergistic mixture of di-nonyl phenyl phosphoric acid and trin-butyl phosphate," Hydrometallurgy, vol. 73, no. 1-2, pp. 63-70, 2004.

[15] T. Yamaguchi, K. Nishimura, T. Shinbo, and M. Sugiura, "Amino aid transport through supported liquid membranes: mechanism and its application to enantiomeric resolution," Bioelectrochemistry and Bioenergetics, vol. 20, no. 1-3, pp. 109123, 1988.

[16] P. Dzygiel, P. Wieczorek, L. Mathiasson, and J. A.. Jönsson, "Enrichment of amino acids by supported liquid membrane extraction using aliquat 336 as a carrier," Analytical Letters, vol. 31, no. 7, pp. 1261-1274, 1998.
[17] M. Rak, P. Dzygiel, and P. Wieczorek, "Supported liquid membrane extraction of aromatic aminophosphonates," Analytica Chimica Acta, vol. 433, no. 2, pp. 227-236, 2001.

[18] M. Di Luccio, B. D. Smith, T. Kida, T. L. M. Alves, and C. P. Borges, "Evaluation of flat sheet and hollow fiber supported liquid membranes for fructose pertraction from a mixture of sugars," Desalination, vol. 148, no. 1-3, pp. 213-220, 2002.

[19] N. Tbeur, T. Rhlalou, M. Hlaíbi, D. Langevin, M. Métayer, and J.-F. Verchère, "Molecular recognition of carbohydrates by a resorcinarene. Selective transport of alditols through a supported liquid membrane," Carbohydrate Research, vol. 329, no. 2, pp. 409-422, 2000.

[20] T. Rhlalou, M. Ferhat, M. A. Frouji, D. Langevin, M. Métayer, and J.-F. Verchère, "Facilitated transport of sugars by a resorcinarene through a supported liquid membrane," Journal of Membrane Science, vol. 168, no. 1-2, pp. 63-73, 2000.

[21] P. Dzygiel and P. Wieczorek, "Extraction of glyphosate by a supported liquid membrane technique," Journal of Chromatography $A$, vol. 889, no. 1-2, pp. 93-98, 2000.

[22] M. Mulugeta and N. Megersa, "Carrier-mediated extraction of bipyridilium herbicides across the hydrophobic liquid membrane," Talanta, vol. 64, no. 1, pp. 101-108, 2004.

[23] R.-S. Juang, R.-H. Huang, and R.-T. Wu, "Separation of citric and lactic acids in aqueous solutions by solvent extraction and liquid membrane processes," Journal of Membrane Science, vol. 136, no. 1-2, pp. 89-99, 1997.

[24] E. Miyako, T. Maruyama, N. Kamiya, and M. Goto, "Transport of organic acids through a supported liquid membrane driven by lipase-catalyzed reactions," Journal of Bioscience and Bioengineering, vol. 96, no. 4, pp. 370-374, 2003.

[25] C. Fontàs, R. Tayeb, M. Dhahbi et al., "Polymer inclusion membranes: the concept of fixed sites membrane revised," Journal of Membrane Science, vol. 290, no. 1-2, pp. 62-72, 2007.

[26] R. W. Baker, Membrane Technology and Applications, John Wiley \& Sons, Chichester, UK, 2012.

[27] A. Benjjar, M. Hor, M. Riri et al., "A new supported liquid membrane (SLM) with methyl cholate for facilitated transport of dichromate ions from mineral acids: parameters and mechanism relating to the transport," Journal of Materials and Environmental Science, vol. 3, no. 5, pp. 826-839, 2012.

[28] A. Benjjar, T. Eljaddi, O. Kamal, L. Lebrun, and M. Hlaibi, "Methyl cholate and resorcinarene new carriers for the recovery of Cr(III) ions by Supported Liquid Membranes (SLM)s," Open Journal of Physical Chemistry, vol. 3, no. 3, pp. 103-114, 2013.

[29] T. Eljaddi, O. Kamal, E. H. E. Atmani, I. Touarssi, L. Lebrun, and M. Hlaïbi, "Effective supported liquid membranes for facilitated extraction phenomenon of cadmium (ii) ions from acidic environments: parameters and mechanism," Canadian Journal of Chemical Engineering, vol. 93, no. 3, pp. 613-621, 2015.

[30] A. Benjjar, T. Eljaddi, O. Kamal, K. Touaj, L. Lebrun, and M. Hlaibi, "The development of new supported liquid membranes (SLMs) with agents: methyl cholate and resorcinarene as carriers for the removal of dichromate ions $\left(\mathrm{Cr}_{2} \mathrm{O}_{7}^{2-}\right)$," Journal of Environmental Chemical Engineering, vol. 2, no. 1, pp. 503-509, 2014.

[31] T. Eljaddi, M. Hor, A. Benjjar et al., "New supported liquid membrane for studying facilitated transport of $\mathrm{U}(\mathrm{VI})$ ions using Tributyl phosphate (TBP) and Tri-n-octylamine (TOA) as carriers from acid medium," BAOJ Chemistry, vol. 1, no. 1, article 003, pp. 1-9, 2015. 

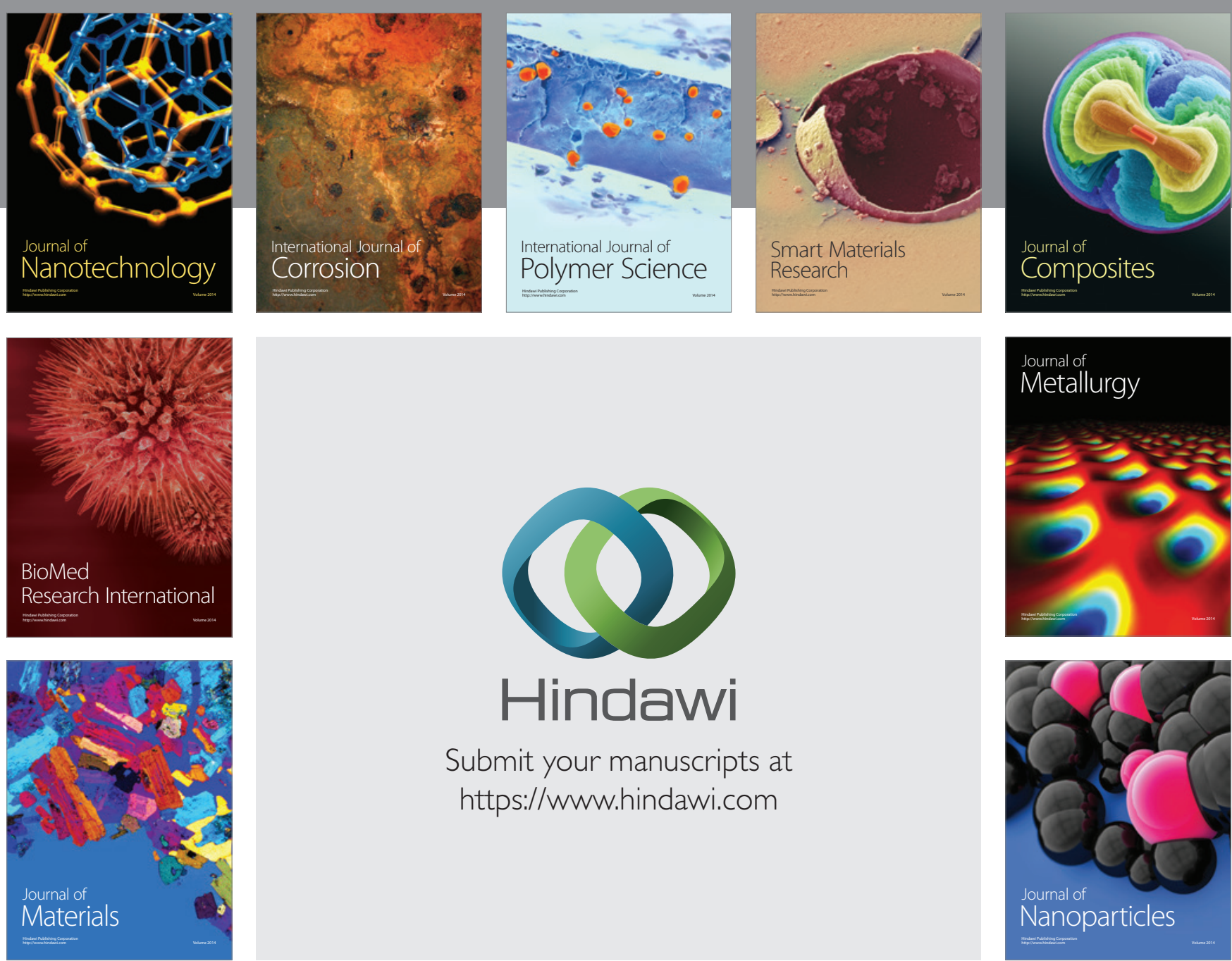

\section{Hindawi}

Submit your manuscripts at

https://www.hindawi.com

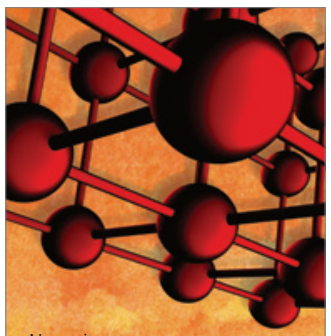

Materials Science and Engineering
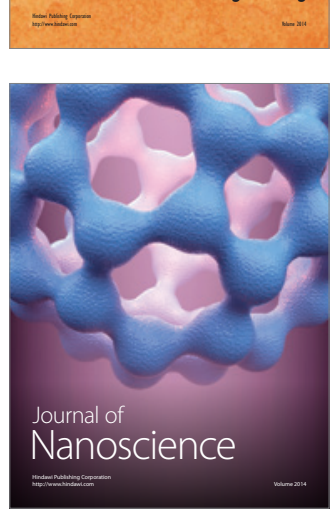
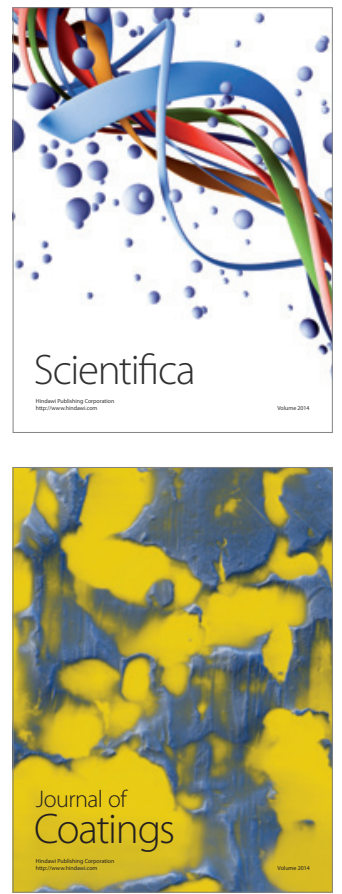
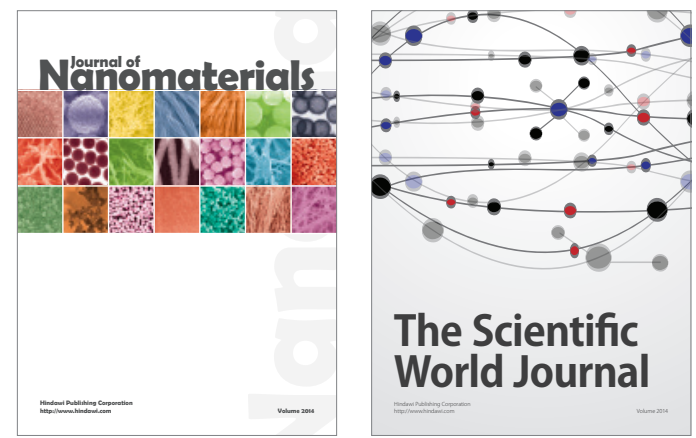

The Scientific World Journal
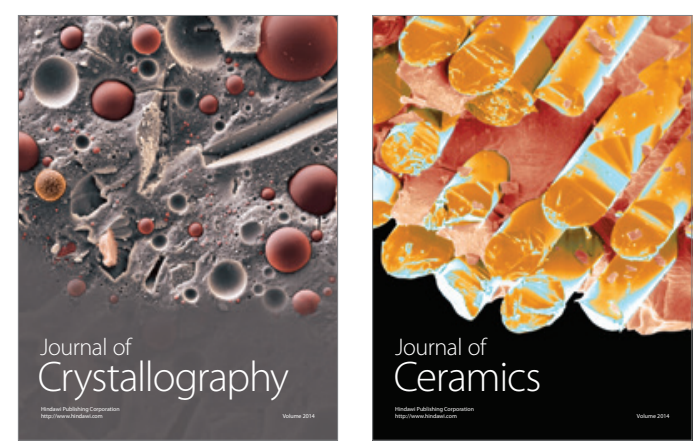
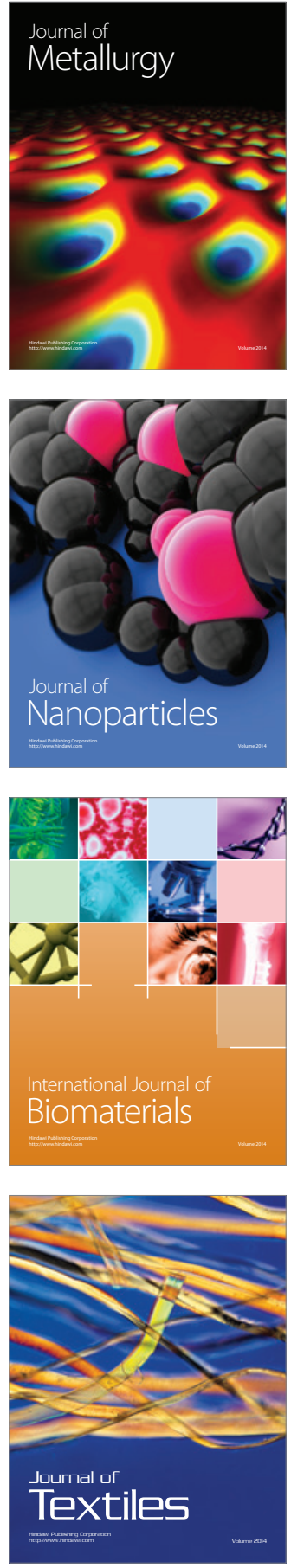